\title{
EFEITOS ADVERSOS E COMORBIDADES ASSOCIADAS AO USO ANTIBIÓTICOS NA POPULAÇÃO PEDIÁTRICA NO INÍCIO DO DESENVOLVIMENTO
}

\section{ARTIGO DE REVISÃO}

SILVA, Antonia Rafaelly Fernandes ${ }^{1}$

MOREIRA, Geterson Bezerra ${ }^{2}$

CARVALHO, Jessica Vieira Marques Petri ${ }^{3}$

CONCEIÇÃO, Eduarda Almeida Dutra da ${ }^{4}$

XAVIER, Camila Duarte ${ }^{5}$

SIMÕES, Henrique Rivera ${ }^{6}$

MANOEL, Poliana Zanotto ${ }^{7}$

MANOEL, Agnes Zanotto ${ }^{8}$

SILVA, Camilla Cristina Vicentini Fernandes da ${ }^{9}$

\footnotetext{
${ }^{1}$ Discente do curso de Medicina do Centro Universitário UNINTA, Sobral - CE.

${ }^{2}$ Cirurgião Geral. Médico Endoscopista. Coordenador da Residência em Cirurgia Sobral - Ceará.

${ }^{3}$ Discente do curso de Medicina.

4 Discente do curso de Medicina.

${ }^{5}$ Discente do curso de Medicina.

${ }^{6}$ Discente do curso de Medicina.

${ }^{7}$ Discente do curso de Medicina.

${ }^{8}$ Discente do curso de Medicina.

${ }^{9}$ Discente do curso de Medicina.
} 
XAVIER, Camila Duarte ${ }^{10}$

SILVA, Antonia Rafaelly Fernandes. Et al. Efeitos adversos e comorbidades associadas ao uso antibióticos na população pediátrica no início do desenvolvimento. Revista Científica Multidisciplinar Núcleo do Conhecimento. Ano 06, Ed. 01, Vol. 03, pp. 124-165. Janeiro de 2021. ISSN: 2448-0959, Link de acesso: https://www.nucleodoconhecimento.com.br/saude/efeitos-adversos

\section{RESUMO}

Introdução: Infecções bacterianas de diversos tipos são eventos comuns na infância, com o índice epidemiológico importante. Dito isso, é necessário estudar os efeitos adversos dos antibióticos, já que são os medicamentos usados no tratamento dessas diversas doenças. $O$ objetivo desse estudo foi fazer uma correlação com os perigos do uso de antibióticos no início da vida e quais comorbidades ela se relaciona no futuro. Métodos: $\mathrm{O}$ artigo em questão consiste em uma revisão bibliográfica do tipo integrativa, de abordagem qualitativa e natureza aplicada. Resultados e Discussão: Cerca de 50\% ( $\mathrm{N}=4)$ dos estudos analisados eram voltados a Terapêutica Antibiótica, apenas um dos estudos era descritivo multicêntrico, foi focado em prescrições médicas e não no decorrer do tratamento, avaliando assim, que houve um aumento no número de prescrições em emergências hospitalares em relação à atenção primária. Analisou-se também que em $60 \%$ dos casos a prescrição era incorreta, entretanto era maior em emergências hospitalares, sendo assim o tratamento era mais adequado na atenção primária. Conclusão: o uso indiscriminado de antibióticos, em casos de amigdalites virais e amigdalectomias, estão efetivamente relacionados ao aumento da resistência antibiótica e impactos a curto e longo prazo na resposta imunológica.

Palavras-chave: Antibióticos, infância, infecção, reação adversa, resistência.

${ }^{10}$ Discente do curso de Medicina. 


\section{INTRODUÇÃO}

As infecções de vias aéreas superiores (IVAS) constituem a causa mais comum dentre afecções que acometem o sistema respiratório e que culminam com a necessidade de auxílio médico em adultos e crianças. A tonsilite aguda é definida como um processo inflamatório que acomete uma ou mais formações linfoides do anel de Wandeyer, sendo que as tonsilas palatinas, também denominadas amígdalas, são acometidas com maior recorrência, contudo é um processo autolimitado em sua grande maioria. (PEREIRA, 2017)

Diversos autores salientam que, dos agentes virais, fazem-se conhecidos os adenovírus, vírus influenza, parainfluenza, rinovírus, coronavírus, coxsackie, vírus sincicial respiratório, herpes vírus e vírus de Epstein-Barr (EBV). Dentre os patógenos bacterianos, o estreptococo beta-hemolítico do grupo A (EBHGA) é considerado o patógeno de maior relevância, responsável pelas frequências de 20 a 30\% das infecções bacterianas e uma evolução que culmina com sequelas supurativas e nãosupurativas, somado ao risco do desenvolvimento de febre reumática. (PEFTI, 2020; PEREIRA, 2017)

É sabido que os sintomas como coriza, congestão nasal, rinorreia, espirros, tosse, rouquidão, aftas e sintomas gastrointestinais associado ou não a elevações de temperaturas corpóreas, estão associadas às doenças virais. Não obstante, as infecções bacterianas apresentam início brusco com febre alta $\left(>38,5{ }^{\circ} \mathrm{C}\right)$, odinofagia intensa associado ao exame físico de orofaringe contendo hiperemia, hipertrofia e exsudato tonsilar, linfadenopatia cervical anterior de subângulo mandibular dolorosa. (PEREIRA, 2017; VIVAS, 2019)

Em virtude da necessidade na distinção quanto o agente etiológico responsável pelo quadro de amigdalite aguda e a fim de afastar infecções bacterianas, o método padrão-ouro para identificação do EBHGA consiste na cultura de orofaringe (possui sensibilidade entre 60-90\% e especificidade entre 65-95\%). No entanto, apesar de ser a opção de escolha diagnóstica, não se faz possível análise instantânea, cerca de 48 a 72 horas, o que retarda o início do estabelecimento de uma terapêutica adequada. 
Testes rápidos de detecção de antígenos estreptocócicos constituem uma eficiente solução por possuírem respostas rápidas. Contudo, não consiste em um método acessível a rede pública pelos altos custos. (PEREIRA, 2017; PILTCHER et al., 2018)

Em virtude da dificuldade para elucidação diagnóstica, métodos clínicos validados e passíveis de reprodução para diferentes faixas etárias, são empregados a fim de identificar potenciais infecções pelo EBHGA. O escore clínico de Centor modificado (Mclsaac), possibilita o cálculo da probabilidade de faringotonsilites bacteriana a partir de dados obtidos na história clínica e do exame físico. Associado a testes como hemograma e dosagem de proteína $C$ reativa $(P C R)$, apesar de não específicos, auxiliam na tomada de conduta, pois sabidamente, os quadros virais cursam com linfocitose e baixos níveis de PCR, em contrapartida, os bacterianos cursam com neutrofilia e níveis elevados de PCR (WINDFUHR et al., 2016; VIVAS, 2019).

O uso de antibiótico para todas as formas bacterianas seria benéfico a fim de que os sintomas fossem abreviados, além disso as patologias bacterianas, em sua maioria (90\% dos casos) tem resolução completa e espontânea dentro de 7 dias (PILTCHER et al., 2018). Desta forma, o uso de antibioticoterapia ficaria resguardada aos casos de maior gravidade. Sendo assim, a terapia antimicrobiana de escolha para o EBHGA é a fenoximetilpenicilina (penicilina $\mathrm{V}$ ) ou a penicilina benzatina, tendo ainda como opção terapêutica a amoxicilina. Frente a falha terapêutica com as penicilinas, as cefalosporinas de primeira geração ou clindamicinas são os grupos eleitos (BRUNTON; HILAL-DANDAN, 2015).

Muitas são as abordagens terapêuticas as quais os pacientes pediátricos podem ser submetidos. No entanto, sabe-se que este grupo possui peculiaridades referentes a metabolização de fármacos e, portanto, a posologia instituída aos mesmos deve ser diferenciada, a fim de minimizar eventos adversos. Ademais, a incidência de reações alérgicas relacionadas ao uso de penicilina e cefalosporina correspondem a $0,7-4 \%$, incluem erupções cutâneas, sintomas gastrointestinais, febre e em casos mais graves angioedema e anafilaxia (BRUNTON; HILAL-DANDAN, 2015). 
Desta forma, a elucidação diagnóstica do quadro deve ser realizada de maneira eficaz, tendo em vista a gravidade obtida a partir de um quadro bacteriano com manejo inadequado. Sendo assim, os aspectos da história e do exame físico podem direcionar quanto à origem viral ou bacteriana, mesmo que com baixa especificidade e sensibilidade consistem no instrumento de triagem inicial de um quadro clínico apresentado, necessário e primordial.

Neste contexto, surgiu a pergunta norteadora deste estudo: "o uso da antibioticoterapia pode causar alterações neuropsicomotoras de desenvolvimento?" Este estudo tem como finalidade determinar se existe relação quanto ao uso do antibiótico na primeira infância, haja vista ao seu frequente emprego, e as possíveis complicações neuropiscomotoras, por meio de uma revisão integrativa.

\section{METODOLOGIA}

O artigo em questão consiste em uma revisão bibliográfica do tipo integrativa, de abordagem qualitativa e natureza aplicada, objetivando a descrição da análise de dados coletados sobre o uso indiscriminado de antibioticoterapia na primeira infância.

As bases de dados usadas foram PubMed® e Biblioteca Virtual de Saúde (BVS), sendo as buscas realizadas no período de 07 de outubro de 2020 até 12 de outubro de 2020. Nessas buscas foram utilizados os descritores contidos no DeCS (Descritores em Ciências da Saúde), relacionados à temática do artigo, que incluem, nessa sequência: "amigdalite", "amigdalites, "agentes antibacterianos", "antibióticos", "agentes antimicobacterianos", "agentes bactericidas", e "crianças". Com desígnio de aperfeiçoar a pesquisa, foram empregados a tais descritores, em inglês, operadores booleanos "AND" e "OR", dando origem a formula de busca: (Tonsillitis OR Tonsillitides) AND (Viral) AND (Antibacterial Agents OR Antibiotic OR Antibiotics OR Antimycobacterial Agents OR Bacteriocidal Agents) AND (children).

Nessa perspectiva, com propósito de refinar a busca e aprimorar os resultados, critérios de elegibilidade foram estabelecidos através da utilização de filtros de inclusão e exclusão. Entre os critérios de inclusão estão: publicações dos últimos 
cinco anos; estudos originais e estudos que retratassem fenômenos secundários ao uso dessas medicações. Além disso, ficaram definidos como critérios de exclusão: efeitos colaterais independente da doença; população adulta e pacientes com comorbidades de base. Durante a busca e a leitura dos artigos, realizados pelos idealizadores deste artigo, em sua primeira etapa foram analisados 80 artigos, segundo título e resumo, e aplicados os critérios de inclusão e exclusão. Após essa etapa, restaram 19 artigos que foram lidos na íntegra e os estudos originais analisados conforme sua confiabilidade segundo, sendo, portanto, selecionados 8 artigos.

Diante disso, é válido salientar que a ordem da pesquisa não é de caráter prático, evidenciando, dessa forma, a dispensa de submissão ao Comitê de Ética em Pesquisa (CEP).

Os resultados da pesquisa serão organizados em quadros contendo título, local, ano de publicação, autor e principais resultados, todos esses dados estarão relacionados ao tema impacto do uso indiscriminado de antibioticoterapia em casos de amigdalite viral.

\section{RESULTADOS}

Quadro 1 - Resultados dos estudos analisados

\begin{tabular}{|l|l|l|l|l|}
\hline Autor, ano & Tipo de Estudo & Intervenção & Resultados \\
\hline Wang et & Estudo & Crianças chinesas & Notou-se que nos três \\
al. (2017) & comparativo & com idades entre 2 & grupos as espécies \\
até 18 anos, de três & bacterianas & mais \\
hospitais da China & prevalentes foram \\
foram separadas em & Staphylococcus aureus e \\
três grupos: as que & Haemophilus influenzae. \\
possuíam tonsilite & Nos grupos com tonsilite \\
recorrente, as que & recorrente e hipertrofia \\
apresentavam & tonsilar não se observou \\
hipertrofia tonsilar e & diferença significativa com
\end{tabular}




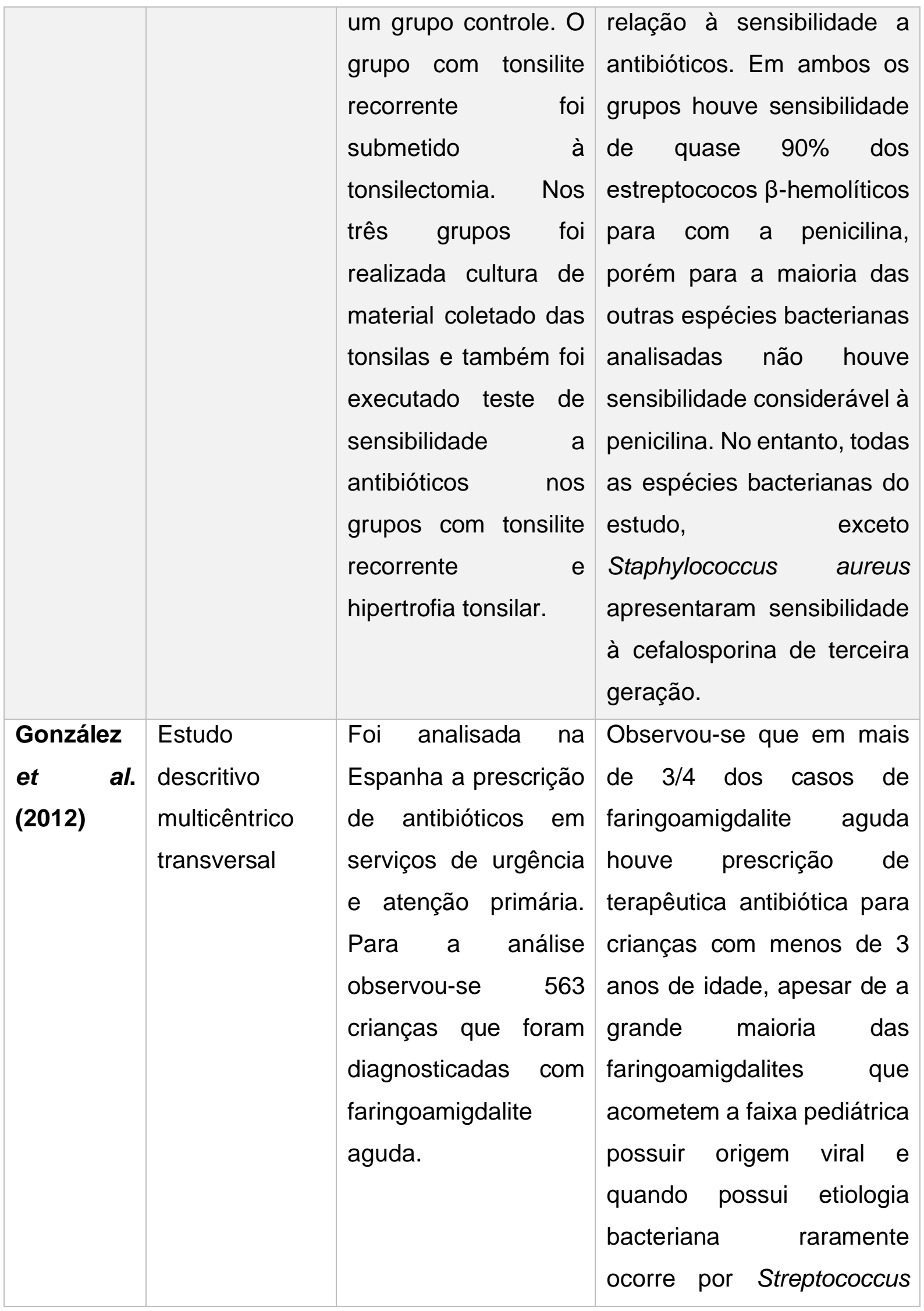




\begin{tabular}{|c|c|c|c|}
\hline & & & $\begin{array}{l}\text { pyogenes em crianças } \\
\text { abaixo de } 3 \text { anos. Além } \\
\text { disso, a terapêutica com } \\
\text { antibióticos foi considerada } \\
\text { incorreta em quase } 60 \% \text { dos } \\
\text { casos analisados e } \\
\text { observou-se também que } \\
\text { nos serviços de urgência há } \\
\text { maior frequência na } \\
\text { prescrição de antibióticos } \\
\text { em relação à prescrição da } \\
\text { atenção primária. }\end{array}$ \\
\hline $\begin{array}{l}\text { Norrby et } \\
\text { al. (2004) }\end{array}$ & $\begin{array}{l}\text { Comparação } \\
\text { entre dois } \\
\text { ensaios } \\
\text { clínicos } \\
\text { multicêntricos, } \\
\text { randomizados, } \\
\text { duplo-cegos }\end{array}$ & $\begin{array}{l}\text { Os estudos avaliaram } \\
\text { pacientes de } 12 \\
\text { países que possuíam } \\
13 \text { anos de idade ou } \\
\text { mais } \\
\text { que apresentavam } \\
\text { tonsilofaringite } \\
\text { estreptocócica. Os } \\
\text { pacientes foram } \\
\text { divididos de forma } \\
\text { randomizada em } \\
\text { grupos. Um grupo } \\
\text { recebeu uma vez por } \\
\text { dia pela manhã } \\
\text { durante o período de } \\
5 \text { dias, } 800 \text { mg de } \\
\text { telitromicina por via } \\
\text { oral e após o término } \\
\text { do tratamento com }\end{array}$ & $\begin{array}{l}\text { De maneira geral em ambos } \\
\text { os estudos houve boa } \\
\text { tolerância em relação à } \\
\text { telitromicina e quando } \\
\text { ocorreram efeitos adversos } \\
\text { foram de graus leve ou } \\
\text { moderado. O tratamento } \\
\text { contra tonsilofaringite } \\
\text { estreptocócica com } 800 \text { mg } \\
\text { de telitromicina, uma vez ao } \\
\text { dia por } 5 \text { dias, apresentou } \\
\text { eficácia similar ao } \\
\text { tratamento de } 10 \text { dias com } \\
\text { penicilina } \quad \mathrm{V} \text { ou } \\
\text { clatritromicina. Contudo, a } \\
\text { telitromicina apresentou } \\
\text { atividade in-vitro superior a } \\
\text { de clatritromicina ou disso, a } \\
\text { azitromicina. Além }\end{array}$ \\
\hline
\end{tabular}




\begin{tabular}{|c|c|c|c|}
\hline & & $\begin{array}{l}\text { essa medicação } \\
\text { receberam por mais } 5 \\
\text { dias comprimidos de } \\
\text { placebo. Um segundo } \\
\text { grupo recebeu } 500 \\
\text { mg de penicilina V, } \\
\text { três vezes ao dia por } \\
10 \text { dias e outro grupo } \\
\text { recebeu } 250 \text { mg de } \\
\text { claritromicina, duas } \\
\text { vezes ao dia por } 10 \\
\text { dias. }\end{array}$ & $\begin{array}{l}\text { terapêutica com } \\
\text { telitromicina demonstrou } \\
\text { como vantagens um } \\
\text { tratamento por período mais } \\
\text { curto e com necessidade de } \\
\text { apenas uma dose diária. }\end{array}$ \\
\hline $\begin{array}{l}\text { Doan et al. } \\
\text { (2019) }\end{array}$ & $\begin{array}{l}\text { Ensaio } \\
\text { comunitário } \\
\text { randomizado }\end{array}$ & $\begin{array}{l}\text { Foram selecionadas } \\
\text { de forma } \\
\text { randomizada } 30 \text { vilas } \\
\text { da Nigéria. Metade do } \\
\text { número total de vilas } \\
\text { recebeu azitromicina } \\
\text { por via oral a cada } 6 \\
\text { meses por } 2 \text { anos a a } \\
\text { outra metade recebeu } \\
\text { placebo também por } \\
\text { via oral a cada } 6 \\
\text { meses por } 2 \text { anos. } \\
\text { Após o término do } \\
\text { período de tratamento } \\
\text { foram coletadas } \\
\text { amostras retais de } \\
600 \text { crianças em } \\
\text { idade pré-escolar } \\
\text { moradoras dessas }\end{array}$ & $\begin{array}{l}\text { Observou-se ao término dos } \\
2 \text { anos de tratamento com } \\
\text { azitromicina } \\
\text { diminuição na variedade de } \\
35 \text { espécies bacterianas da } \\
\text { microbiota intestinal das } \\
\text { crianças. Campylobacter } \\
\text { upsaliensis demonstrou-se } \\
\text { consideravelmente reduzida } \\
\text { nas crianças que foram } \\
\text { tratadas com azitromicina } \\
\text { em relação às que } \\
\text { receberam placebo. Além } \\
\text { disso, apesar de a } \\
\text { azitromicina reduzir os } \\
\text { níveis de mortalidade das } \\
\text { crianças que a recebem, por } \\
\text { meio do sequenciamento } \\
\text { metagenômico de RNA de }\end{array}$ \\
\hline
\end{tabular}




\begin{tabular}{|c|c|c|c|}
\hline & & $\begin{array}{l}\text { vilas. As amostras } \\
\text { foram submetidas } \\
\text { posteriormente a } \\
\text { sequenciamento } \\
\text { metagenômico de } \\
\text { RNA. }\end{array}$ & $\begin{array}{l}300 \text { amostras retais } \\
\text { realizado seis meses após o } \\
\text { fim do tratamento observou- } \\
\text { se expressão significativa } \\
\text { de genes de resistência aos } \\
\text { macrolídeos quando } \\
\text { comparou-se ao uso de } \\
\text { placebo. }\end{array}$ \\
\hline $\begin{array}{l}\text { Der M et } \\
\text { al. (2007) }\end{array}$ & $\begin{array}{l}\text { Estudo } \\
\text { prospectivo, } \\
\text { comparativo, } \\
\text { controlado e } \\
\text { cego }\end{array}$ & $\begin{array}{l}\text { Foram analisadas } \\
\text { crianças de ambos os } \\
\text { sexos com idades de } \\
4 \text { a } 10 \text { anos. Foram } \\
\text { divididas em grupo } \\
\text { caso as crianças que } \\
\text { apresentavam } \\
\text { amigdalite bacteriana } \\
\text { recorrente aguda e } \\
\text { indicação cirúrgica e } \\
\text { no grupo controle as } \\
\text { crianças com apneia } \\
\text { do sono e que } \\
\text { também possuíam } \\
\text { indicação cirúrgica. } \\
\text { Ambos os grupos } \\
\text { foram submetidos a } \\
\text { amigdalectomia e as } \\
\text { peça cirúrgicas foram } \\
\text { enviadas para } \\
\text { realização de cultura } \\
\text { e antibiograma. }\end{array}$ & $\begin{array}{l}\text { Estatisticamente não houve } \\
\text { diferença significativa entre } \\
\text { as cepas bacterianas dos } \\
\text { dois grupos. As bactérias } \\
\text { mais encontradas foram } \\
\text { Haemophilus influenzae, } \\
\text { Staphylococcus aureus } \\
\text { e Streptococcus pyogenes. } \\
\text { Para os estreptococos beta- } \\
\text { hemolíticos dos grupos A e } \\
\text { e pneumococo foi } \\
\text { encontrada sensibilidade de } \\
100 \% \text { in vitro a antibióticos } \\
\text { das classes dos beta- } \\
\text { lactâmicos e macrolídeos. } \\
\text { Já com relação ao } S \text {. aureus } \\
\text { nos indivíduos do grupo } \\
\text { controle também houve } \\
\text { sensibilidade de } 100 \% \text { aos } \\
\text { macrolídeos e beta- } \\
\text { lactâmicos e no grupo caso } \\
\text { a sensibilidade do } S \text {. aureus }\end{array}$ \\
\hline
\end{tabular}




\begin{tabular}{|c|c|c|c|}
\hline & & & $\begin{array}{l}\text { apresentou percentual de } \\
87 \% \text {. }\end{array}$ \\
\hline $\begin{array}{l}\text { Cohen } \\
\text { (2004) }\end{array}$ & $\begin{array}{l}\text { Estudo } \\
\text { comparativo } \\
\text { por meio de } \\
\text { Revisão de } \\
\text { literatura }\end{array}$ & $\begin{array}{l}\text { Foram comparados } \\
12 \quad \text { estudos } \\
\text { prospectivos } \\
\text { randomizados } \\
\text { realizados entre } 1993 \\
\text { e } 2002 \text { em que se } \\
\text { analisou crianças com } \\
\text { tonsilofaringite } \\
\text { estreptocócica e se } \\
\text { comparou a eficácia } \\
\text { do tratamento e } \\
\text { erradicação } \\
\text { bacteriana com o uso } \\
\text { de azitromicina } \\
\text { comparando ao uso } \\
\text { principalmente de } \\
\text { penicilina V. }\end{array}$ & $\begin{array}{l}\text { Evidências têm } \\
\text { demonstrado que crianças } \\
\text { com tonsilofaringite } \\
\text { estreptocócica podem } \\
\text { receber tratamento com } \\
\text { azitromicina } 12 \mathrm{mg} / \mathrm{kg} \text { uma } \\
\text { vez ao dia por período de } 5 \\
\text { dias ou } 20 \mathrm{mg} / \mathrm{kg} \text { uma vez } \\
\text { ao dia por } 3 \text { dias. Esse } \\
\text { regime terapêutico } \\
\text { apresenta ótima taxa de } \\
\text { erradicação bacteriana } \mathrm{e} \\
\text { apresenta-se mais prático } \\
\text { por necessitar de apenas } \\
\text { uma dose diária e menos } \\
\text { dia de tratamento quando } \\
\text { comparado ao tratamento } \\
\text { padrão de } 10 \text { dias com } \\
\text { penicilina } \mathrm{V} \text {. }\end{array}$ \\
\hline $\begin{array}{l}\text { Chazan et } \\
\text { al. (2015) }\end{array}$ & $\begin{array}{l}\text { Estudo } \\
\text { comparativo }\end{array}$ & $\begin{array}{l}\text { Em 2011, em Israel, } \\
\text { foram coletadas } \\
\text { amostras da faringe } \\
\text { de } 300 \text { pacientes que } \\
\text { possuíam o } \\
\text { Streptococcus } \\
\text { pyogenes, sendo } 208 \\
\text { amostras de crianças } \\
\text { e } 92 \text { de adultos. As } \\
\text { amostras foram }\end{array}$ & $\begin{array}{l}\text { A susceptibilidade do } S \text {. } \\
\text { pyogenes aos antibióticos } \\
\text { continuou com alto valor e } \\
\text { com resultados } \\
\text { semelhantes aos da } \\
\text { pesquisa realizada em } \\
\text { 2004. Apesar de em } 2011 \\
\text { ter havido aumento da } \\
\text { concentração mínima } \\
\text { inibitória (MIC90) de }\end{array}$ \\
\hline
\end{tabular}




\begin{tabular}{|c|c|c|c|}
\hline & & $\begin{array}{l}\text { submetidas à cultura } \\
\text { e teste de } \\
\text { sensibilidade aos } \\
\text { antibióticos: } \\
\text { penicilina, } \\
\text { macrolídeos, } \\
\text { clindamicina } \\
\text { tetraciclina com o } \\
\text { objetivo de comparar } \\
\text { os achados de } \\
\text { sensibilidade } \\
\text { antibióticos com os } \\
\text { resultados } \\
\text { sensibilidade } \\
\text { coletados em } 2004 \\
\text { em lsrael e em outros } \\
\text { locais. }\end{array}$ & $\begin{array}{l}\text { azitromicina com relação ao } \\
S \text {. pyogenes ainda é } \\
\text { mantida a recomendação do } \\
\text { uso desse antibiótico para } \\
\text { tratamento } \\
\text { faringotonsilite } \\
\text { estreptocócica, contudo } \\
\text { deve-se realizar a } \\
\text { monitorização } \\
\text { aumento. Ressalta-se ainda } \\
\text { que é essencial a vigilância } \\
\text { periódica dos níveis de } \\
\text { sensibilidade do } S \text {. } \\
\text { pyogenes aos } \\
\text { antimicrobianos. }\end{array}$ \\
\hline $\begin{array}{l}\text { Hammond } \\
\text { et al. } \\
(2020)\end{array}$ & $\begin{array}{l}\text { Modelo de } \\
\text { investigação de } \\
\text { regressão } \\
\text { logística } \\
\text { multinível }\end{array}$ & $\begin{array}{l}\text { Realizou-se pesquisa } \\
\text { na Inglaterra na } \\
\text { atenção primária à } \\
\text { saúde buscando } \\
\text { encontrar relações } \\
\text { entre a dispensação } \\
\text { de antibióticos para } \\
\text { cerca de } 1.5 \text { milhão } \\
\text { de pacientes e a } \\
\text { resistência de } \\
\text { Escherichia coli a } \\
\text { antimicrobianos em } \\
\text { quase } 153 \text { mil } \\
\text { amostras de urina por }\end{array}$ & $\begin{array}{l}\text { Observou-se que houve } \\
\text { redução de } 11 \% \text { na } \\
\text { dispensação de antibióticos } \\
\text { por mil pacientes. A } \\
\text { dispensação de co- } \\
\text { amoxiclav reduziu em quase } \\
50 \% \text { no entanto a } \\
\text { dispensação } \\
\text { nitrofurantoína aumentou } \\
\text { em 7\%. A diminuição na } \\
\text { dispensação de antibióticos } \\
\text { demonstrou relação com a } \\
\text { redução em 25\% na } \\
\text { resistência à amoxicilina, }\end{array}$ \\
\hline
\end{tabular}




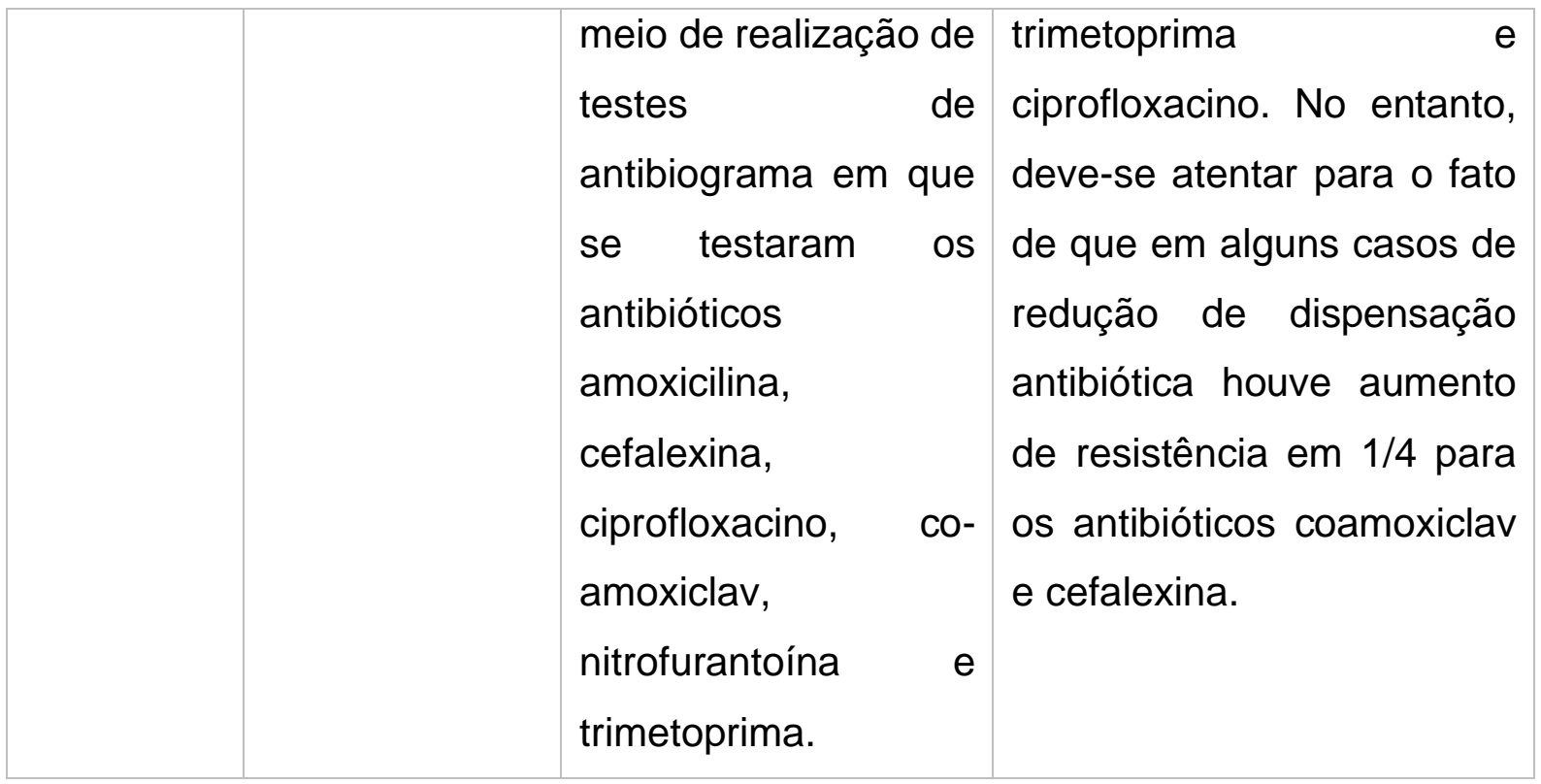

Fonte: Elaborado pelo autor (2020)

Foram analisados 8 estudos, a maior fração deles era voltado ao estudo comparativo. Dentre os estudos analisados, $50 \%(\mathrm{~N}=4)$, eram voltados a Terapêutica Antibiótica, e $37,5 \%(\mathrm{~N}=3)$; apresentaram dados sobre a Sensibilidade à Antibióticos, e um dos estudos avaliou dados de Intervenção Cirúrgica. Os estudos estabeleceram as seguintes categorias para uma avaliação dos resultados.

\subsection{TERAPÊUTICA ANTIBIÓTICA}

Cerca de $50 \%(\mathrm{~N}=4)$ dos estudos analisados eram voltados a Terapêutica Antibiótica, apenas um dos estudos (GONZÁLEZ et al., 2012), um estudo era descritivo multicêntrico, foi focado em prescrições médicas e não no decorrer do tratamento, avaliando assim, que houve um aumento no número de prescrições em emergências hospitalares em relação à atenção primária. Analisou-se também que em $60 \%$ dos casos a prescrição era incorreta, entretanto era maior em emergências hospitalares, sendo assim o tratamento era mais adequado na atenção primária. Apesar do antibiótico ser a primeira escolha em 184 dos casos (43,3\% dos tratados) do total de pacientes analisados, mesmo sendo viral e não bacteriana o processo infeccioso das faringoamigdalites. Não houve aumento ou diminuição no número de prescrições por 
cada médico prescritor, entretanto houve uma melhor adequação das prescrições feitas.

Outros dois estudos (NORRBY et al., 2004; COHEN, 2004) analisaram o período do tratamento, o primeiro avaliou dois estudos onde pacientes foram divididos em dois grupos, onde um grupo recebeu tetraciclina e o outro recebeu comparadores, os pacientes foram pareados em termos demográficos, o resultado revelou que $88,3 \%$ dos pacientes tratados com a teliomicina tiveram um resultado bacteriológico mais adequado em relação aos $88,6 \%$ dos pacientes tratados com o comparador. Já no resultado clínico também foi observado uma significativa superioridade em relação ao comparador, com uma taxa de cura de $92,7-94,8 \%$, semelhante a taxa de cura de $94,1 \%$ em pacientes tratados com penicilina $\mathrm{V}$ e a taxa de cura de $91,1 \%$ em pacientes tratados com claritromicina. Os resultados se confirmaram em um segundo ensaio que as taxas foram $89,6 \%$ para pacientes tratados com telitromicina e $87,3 \%$ para os pacientes tratados com claritromicina. Confirmando assim a eficácia do tratamento mais curto e com dose diária da telitromicina e suas vantagens.

O segundo, respectivamente, demonstrou a importância da morte bacteriana para a cura clínica, apresentando como a utilização de antibióticos pode levar a erradicação bacteriana dos patógenos levando assim a cura, demonstrou também o tratamento com a penicilina $v$ e suas falhas, além de como a penicilina tem decrescido nas prescrições devido a suas falhas e desvantagens, apresentando falhas nos tratamentos das faringites em $35 \%$, principalmente em crianças. Além do número de pessoas alérgicas a penicilina que necessitam de outro medicamento eficaz, demonstrou ainda o uso da azitromicina na faringite de GABHS, a análise apresentou eficácia da azitromicina em $90 \%$ em relação a eficácia clínica e em erradicação bacteriana, Ademais apresentou a importância dos tratamentos alternativos para a penicilina para atingir uma maior eficácia clínica, além de aumentar as taxas de erradicação bacteriana. A resistência a macrolídeos também foi apresentada como uma preocupação por conta que o tratamento da amigdalofaringite por GABHS ainda não tem dados que provem que as taxas de eficácia ou falha tanto clínica quanto de erradicação bacteriana em pacientes previamente sensíveis a penicilina. 
No estudo de Doan et al. (2019), um estudo randomizado, que foi o único analisado a abordar o uso de placebo durante o tratamento, os resultados foram a redução na mortalidade entre as crianças que receberam a Azitromicina oral semestral em comparação às que receberam placebo semestral, entretanto afetou a microbiota intestinal das crianças que obtiveram a medicação, as bactérias foram reduzidas significativamente também nas crianças que receberam Azitromicina, mostrando que a distribuição em massa de Azitromicina reduz não só as bactérias intestinais como também possíveis patógenos. Foi observado também que na Nigéria, local do estudo, a microbiota que as crianças apresentavam ser relacionados a sobrevivência no local.

\subsection{SENSIBILIDADE À ANTIBIÓTICOS}

A sensibilidade à antibióticos foi observada em $37,5 \%(\mathrm{~N}=3)$ dos estudos analisados, dois deles foram estudos comparativos, que abordavam a comparação entre os antibióticos demonstrando em números quais os antibióticos que resultavam e maior quantidade de pessoas sensibilizadas.

No estudo de Hammond et al. (2020), dados mostram que entre 2013 e 2016, houve redução na distribuição de dos antibióticos a nível da pratica, analisou-se 1000 pacientes teve sua dispersão de antibióticos reduzidos em 11\%, co-amoxiclav reduziu, $49 \%$ sendo assim o medicamento com maior redução, amoxicilina reduziu $14 \%$; cefalexina 20\%; ciprofloxacina 24\%; e trimetoprima $8 \%$. A dispensação de nitrofurantoína foi a única que aumentou, um total de $7 \%$. Dados da microbiologia foram fornecidos para 163 práticas de cuidados primários, onde foram colhidos dados de 152. 704 amostras de urina contendo E. coli. foram cultivadas. Foram testados para resistência à insulina e apresentaram dados onde a resistência a amoxilina foram de $52 \%$ e trimetropina $36 \%$.

O estudo de Wang et al. (2017), o estudo incluiu 1.208 crianças RT, 932 crianças TH e 854 controles, os grupos foram testados e não apresentaram diferenças significativas nas cepas individuais. Nos dois grupos houve sensibilidade de aproximadamente $90 \%$ dos estreptococos $\beta$-hemolíticos para com a penicilina, porém não para as outras espécies bacterianas não houve resistência a penicilina. Não 
houve diferenças na resistência aos antibióticos nos grupos RT e TH. Entretanto todas as espécies bacterianas do estudadas, exceto $S$. aureus apresentaram sensibilidade à cefalosporina de terceira geração em quase 100\%. Todas as cepas mostraram resistência a macrolídeo, gentamicina e vancomicina, quinolonas, exceto para resposta fraca de S. pneumoniae para macrolídeo.

Chazan et al. (2015), apresentou no seu estudo 300 amostras da faringe que possuíam o S. pyogenes, sendo 208 de crianças e 92 adultos. Dentre eles 295 foram sensíveis a todos os antibióticos testados (Penicilina, Tetraciclina, Eritromicina, Clindamicina e Azitromicina). Dos 300 testados, 3 foram resistentes somente a tetraciclina, 1 a ambos os macrolídeos testados, eritromicina e azitromicina e 1 apresentou sensibilidade intermediária à clindamicina. Nenhuma resistência combinada entre medicamentos foi encontrada. $O$ teste foi negativo para todos os 300 testados.

\subsection{INTERVENÇÃO CIRÚRGICA}

Quanto a abordagem cirúrgica, temos o estudo de Der et al. (2007). Este trabalho apresentou a intervenção cirúrgica utilizada (amigdalectomia), que foi o meio pelo qual as estatísticas pós cirúrgicas mostraram que os dois grupos submetidos a cirurgia não obtiveram diferenças entre as cepas bacterianas, avaliou-se também a sensibilidade, onde os resultados apresentaram percentuais altos entre $87-100 \%$ de sensibilidade vinda das bactérias testadas em relação aos antibióticos utilizados antes da intervenção cirúrgica.

\section{DISCUSSÃO}

Mediante dados encontrados em estudo de revisão bibliográfica integrativa, tem-se que: 


\subsection{TERAPÊUTICA ANTIBIÓTICA}

Com respeito a antibioticoterapia é de extrema importância no combate à cepas bacterianas e consequente cura clínica de diversas doenças, principalmente em processos infecciosos. No entanto, a literatura revela que existe uma prescrição excessiva e inadequada de antibióticos, mesmo quando seu uso para tratamento não deve ser realizado. Esse fator demonstra que a etiologia da doença, a possibilidade de efeitos adversos, além de cuidados adicionais, que devem ser mais precisamente analisados na população pediátrica, não estão sendo realizados de maneira apropriada (GONZÁLEZ, et al., 2012; PAGANOTTI et al., 2013). Nesse sentido, há uma ilustração clara deste quadro, ao se abordar a terapêutica antibiótica nas infecções respiratórias agudas, em crianças menores de 5 anos (BRICKS, 2003).

A dificuldade de distinção de infecções de origem viral da bacteriana proporciona uma ineficácia no tratamento da doença, visto que o diagnóstico é feito erroneamente, portanto não há melhoria do paciente, além de colocar em risco a saúde da criança e contribuir, indiretamente, para uma possível resistência bacteriana. Também é apontado como erros na terapia com antibióticos a prescrição de doses inadequadas. (PAGANOTTI et al., 2013; BRICKS, 2003).

Por outro lado, é notório que o uso de antibióticos em determinados casos pode contribuir positivamente para a pediatria. A administração oral de Azitromicina em comparativo com o placebo (DOAN et al., 2019), trouxe resultados positivos, visto que houve redução da mortalidade das crianças - mesmo tendo afetado a microbiota intestinal.

Tratamentos mais curtos com antibióticos apresentam maiores vantagens (NORRBY et al., 2004), na terapêutica de tonsilofaringite estreptocócica com telitromicina. Além de já possuir uma boa tolerância e efeitos colaterais leves ou moderados, seu tempo uso é menor que penicilina, por exemplo, e apresenta a mesma eficácia.

O comparativo entre tratamento curto e prolongado de antibióticos - abrangendo pacientes pediátricos - e ratifica que, de fato, deve ser incentivada a prescrição de 
antibióticos de tratamento curto, por apresentar menos efeitos adversos, provocar menos resistência e menor incidência de colite membranosa, além de outros benefícios, como menor custo financeiro (SOUSA, 2020)

Em relação às limitações do presente estudo, há de se afirmar que a escassa presença de artigos na literatura que incluem, propriamente, as comorbidades e efeitos adversos com o uso de antibióticos na primeira infância, contribuiu para que os achados do resultados se distanciassem do objetivos do estudo. A maioria das pesquisas englobam avaliação da sensibilidade de bactérias a antibióticos específicos e da eficácia terapêutica em comparação com fármacos e/ou placebos. Há a necessidade da realização de maiores estudos acerca das comorbidades e efeitos indesejados provocados pelo uso de antibióticos nas crianças.

\subsection{SENSIBILIDADE À ANTIBIÓTICOS E INTERVENÇÃO CIRÚRGICA}

Pode-se observar que, atualmente, a sensibilidade aos antibióticos tem se tornado um assunto de demasiada importância, haja vista que, infecções causadas por bactérias multirresistentes estão diretamente associadas a taxas superiores de mortalidade, complicações, permanência hospitalar e custo de tratamento. Com isso, torna-se essencial a realização de estudos capazes delimitar situações na qual a prescrição de antibióticos é, de fato, indispensável (DAVEY et al., 2017).

Dessa forma, analisando os artigos selecionados, foi possível observar se o uso indiscriminados de antibióticos em casos de amigdalites virais e amigdalectomias, estão associados ao aumento da resistência antibiótica.

No estudo Hammond et al. (2020), foram analisados seis antibióticos; três deles amoxicilina, ciprofloxacina e trimetoprima - apresentaram uma redução da resistência frente a uma diminuição na distribuição; dois deles - co-amoxiclav e cefalexina apresentaram um aumento da resistência frente a uma diminuição na distribuição; um deles - nitrofurantoína - apresentou uma diminuição da resistência frente a um aumento na distribuição. Já os estudos Wang et al. (2017) e Chazan et al. (2015), não foi possível estabelecer uma associação direta entre as taxas de distribuição e 
sensibilidade, pois os resultados apontam que, de modo geral, a sensibilidade das bactérias, responsáveis pelas infecções analisadas, frente aos antibióticos descritos, é expressiva e não apresentam diferenças significativas entre elas.

Em casos de intervenções cirúrgicas, amigdalectomias, também não foi possível delimitar uma correlação entre a sensibilidade e o uso de antibióticos, tendo em vista que, no estudo de Der et al. (2007), os dois grupos submetidos a cirurgia apresentaram percentuais de sensibilidade superiores a $86 \%$.

\section{CONSIDERAÇÕES FINAIS}

Constituindo a causa mais comum dentre as comorbidades que acometem o sistema respiratório, as infecções de vias aéreas superiores (IVAS) foram tema deste estudo de revisão bibliográfica do tipo integrativa de abordagem qualitativa e natureza aplicada, que objetivou descrever, analiticamente, dados coletados sobre o uso indiscriminado de antibioticoterapia em amigdalites virais.

Partindo da pergunta motora "o uso da antibioticoterapia pode causar alterações neuropsicomotoras de desenvolvimento?" foi avaliado por meio de uma revisão integrativa a existente relação quanto ao uso de antibióticos e as complicações possíveis devido ao seu frequente emprego na primeira infância. Desse modo, foram abordados três pontos principais de comparação: Terapêutica Antibiótica, Sensibilidade à Antibióticos e Intervenção Cirúrgica.

O primeiro tópico avaliado resultou no reconhecimento de uma prescrição excessiva e inadequada do medicamento apesar de seu uso ser, teoricamente, resguardado aos casos de maior gravidade. Contudo, a dificuldade de distinção de infecções de origem viral da bacteriana proporciona uma prescrição errônea com seu desperdício e consequente ineficácia, não somente com conservação do quadro do paciente, como também sua exposição ao risco de uma possível resistência bacteriana.

Quanto a sensibilidade à antibióticos, foi avaliada a associação direta entre o desenvolvimento de bactérias multirresistentes e as taxas superiores de mortalidade, 
complicações, permanência hospitalar e custo de tratamento. Dessa maneira, foi possível observar que o uso indiscriminado de antibióticos, em casos de amigdalites virais e amigdalectomias, estão efetivamente relacionados ao aumento da resistência antibiótica. Por fim, foi avaliado a intervenção cirúrgica em amigdalectomias, entretanto não foi possível delimitar uma correlação entre os dois tópicos prévios.

\section{REFERÊNCIAS}

BRICKS, Lucia Ferro. Uso judicioso de medicamentos em crianças. Jornal de Pediatria, [S.L.], v. 79, p. 107-114, jun. 2003. FapUNIFESP (SciELO). http://dx.doi.org/10.1590/s0021-75572003000700012.

BRUNTON, Laurence L; HILAL-DANDAN, Randa. Penicilinas, cefalosporinas e outros antibióticos B-lactâmicos. In: Manual de Farmacologia e Terapêutica de Goodman \& Gilman. $2^{\mathrm{a}}$ ed. Porto Alegre, RS: AMGH, 2015. p. 894-912

CHAZAN, Bibiana et al. Susceptibility of Group AStreptococcusto Antimicrobial Agents in Northern Israel: a surveillance study. Microbial Drug Resistance, [S.L.], v. 21, n. 5, p. 551-555, out. 2015. Mary Ann Liebert Inc. http://dx.doi.org/10.1089/mdr.2015.0040.

COHEN, Robert. Defining the optimum treatment regimen for azithromycin in acute tonsillopharyngitis. The Pediatric Infectious Disease Journal, [S.L.], v. 23, n., p. 129134, fev. 2004. Ovid Technologies (Wolters Kluwer Health). http://dx.doi.org/10.1097/01.inf.0000112527.33870.0d.

DAVEY, Peter et al. Interventions to improve antibiotic prescribing practices for hospital inpatients. Cochrane Database Of Systematic Reviews, [S.L.], 9 fev. 2017.

DER M, Carolina et al. Amigdalitis aguda recurrente bacteriana: estudio prospectivo, comparativo y controlado de sus características clínicas y microbiológicas. Revista de Otorrinolaringología y Cirugía de Cabeza y Cuello, [S.L.], v. 67, n. 1, p. 38-45, abr. 2007. SciELO Agencia Nacional de Investigacion y Desarrollo (ANID). http://dx.doi.org/10.4067/s0718-48162007000100007. 
DOAN, T. et al. Gut microbiome alteration in MORDOR I: a community-randomized trial of mass azithromycin distribution. Nature Medicine, [S.L.], v. 25, n. 9, p. 13701376, 12 ago. 2019. Springer Science and Business Media LLC. http://dx.doi.org/10.1038/s41591-019-0533-0.

GONZÁLEZ, Nuria Fernandez et al. Variabilidad e idoneidad en el tratamiento antimicrobiano de las faringoamigdalitis agudas pediátricas en Asturias, España. Archivos Argentinos de Pediatria, [S.L.], v. 110, n. 03, p. 207-213, 1 jun. 2012. Sociedad Argentina de Pediatria. http://dx.doi.org/10.5546/aap.2012.207.

HAMMOND, Ashley et al. Antimicrobial resistance associations with national primary care antibiotic stewardship policy: primary care-based, multilevel analytic study. Plos One, [S.L.], v. 15, n. 5, e0232903, 14 maio 2020. Public Library of Science (PLoS). http://dx.doi.org/10.1371/journal.pone.0232903.

NORRBY, S.R. et al. Evaluation of 5-day therapy with telithromycin, a novel ketolide antibacterial, for the treatment of tonsillopharyngitis. Clinical Microbiology And Infection, [S.L.], v. 10, n. 7, p. 615-623, jul. 2004. Elsevier BV. http://dx.doi.org/10.1111/j.1469-0691.2004.00908.x

PAGANOTTI, Andreia Maria et al. Prescrição de antibióticos a crianças atendidas no inverno em Unidade de Saúde de município paulista. Revista Ciência Farmarcologia Basica, São Paulo, 2013;34(3): 441-447

PEFTI, Yuliia; FEDOTOV, Oleh. ANALYSIS OF THE AETIOLOGY AND SYMPTOMATICS OF THE CLINICAL CASE OF TONSILITE. International Scientific Conference, [S.L.], p. 88-91, 2020. Publishing House "Baltija Publishing". http://dx.doi.org/10.3052/978-9934-588-39-6-28.

PEREIRA, Maria Beatriz Rotta et al. Tratado de Pediatria: Sociedade Brasileira de Pediatria. Barueri, SP; Manole, 2017. p.1677-1682

PILTCHER, Otávio Bejzman et al. How to avoid the inappropriate use of antibiotics in upper respiratory tract infections? A position statement from an expert panel. Brazilian 
Journal Of Otorhinolaryngology, [S.L.], v. 84, n. 3, p. 265-279, maio 2018. Elsevier BV. http://dx.doi.org/10.1016/j.bjorl.2018.02.001.

SOUSA, Italo Rossy. COMPARAÇÃO ENTRE TRATAMENTO CURTO E TRATAMENTO PROLONGADO DE ANTIBIÓTICOS: revisão integrativa. 2020. 20 p. TCC (Residência) - Curso de Residência Medica Intensiva, Hospital Geral de Fortaleza, Fortaleza, 2020.

VIVAS, Rosa Fornes et al., Utilidad de los criterios clínicos para el adecuado diagnóstico de la faringoamigdalitis en la urgencia pediátrica. Rev. Esp. Salud Publica, Madrid, v. 93, e201911061, 2019.

WANG, Qian et al. Bacteriology and antibiotic sensitivity of tonsillar diseases in Chinese children. European Archives Of Oto-Rhino-Laryngology, [S.L.], v. 274, n. 8, p. 3153-3159, 27 maio 2017. Springer Science and Business Media LLC. http://dx.doi.org/10.1007/s00405-017-4603-y.

WINDFUHR, Jochen P. et al. Clinical practice guideline: tonsillitis i. diagnostics and nonsurgical management. European Archives Of Oto-Rhino-Laryngology, [S.L.], v. 273, n. 4, p. 973-987, 11 jan. 2016. Springer Science and Business Media LLC. http://dx.doi.org/10.1007/s00405-015-3872-6.

Enviado: Dezembro, 2020.

Aprovado: Janeiro, 2021. 